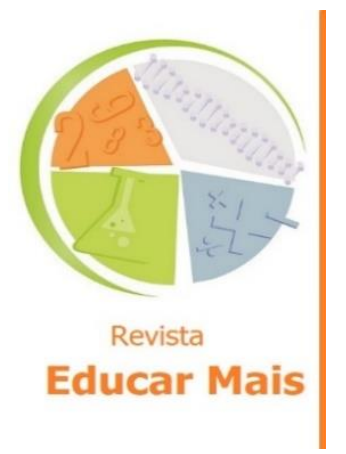

\title{
Movimento Physics First: uma herança positivista?
}

\author{
Physics First Movement: would it be a positivist inheritance?
}

Jenner Barretto Bastos Filho'; Neusa Teresinha Massoni²

\section{RESUMO}

O objetivo precípuo deste trabalho é pesquisar eventuais e/ou reais influências exercidas pelo positivismo de lavra comtiana no movimento Physics First. Explora-se a semelhança da reivindicação veemente do movimento Physics First em prol de um ensino das ciências seguindo a ordem cronológica Física-Química-Biologia com a ordem ensejada pela classificação das ciências de Comte. Conexões entre os planos pedagógicos e epistemológicos são discutidas. Argumenta-se que embora a ciência e epistemologia modernas não respaldem a filosofia positivista que submete a imaginação e a conjectura a um estatuto inferior àqueles dos dados imediatos da observação, ainda assim há elementos bastante relevantes em ambos, no movimento Physics First e no positivismo, e que sugerem atalhos cognitivos e matrizes de pré-requisitos disciplinares compatíveis com uma crescente divisão social do trabalho. Assevera-se ainda que tal influência não deve ser demonizada.

Palavras-chave: Movimento Physics First; Epistemologia; Positivismo; Ensino de Física.

\begin{abstract}
The aim of this paper is the search of eventual and/or real influence exerted by Comte's positivistic philosophy on the motion Physics First. It is explored the similitude between, on one side, the claiming in favor of the practice of the science teaching according to the chronological order Physics-Chemistry-Biology and, on the other, the Comte's classification of science following the order from the simplicity to the growing complexity. Connections between pedagogical and epistemological plans are discussed. It is argued that, in spite of the development of modern science and epistemology do not agree with positivistic claims of major status attributed to observation than speculation and imagination, it is possible to conclude that both, Physics First and positivism, present relevant aspects concerning simplification of the teaching and the knowledge due to a growing social division of the work. This influence must be considered and not demonized.
\end{abstract}

Keywords: Physics First Movement; Epistemology; Positivism; Physics Teaching.

\section{INTRODUÇÃO}

Existe muito desconhecimento, em nossos dias, sobre o que a ciência produz e sobre quais as implicações da ciência e da tecnologia na vida das pessoas. Nas últimas décadas, a pesquisa em ensino de ciências, em especial de Física, tem em boa medida atribuído esta situação à ausência nos currículos de ensino de ciências de uma perspectiva de aprendizagem que inclua, além dos conteúdos

\footnotetext{
${ }^{1}$ UFAL - Instituto de Física e Programa de Pós-Graduação em Ensino de Ciências e Matemática, Maceio/AL - Brasil.

2 UFRGS - Instituto de Física e Programa de Pós-Graduação em Ensino de Física, Porto Alegre/RS - Basil.
} 
de ciências, algo sobre ciências, sua natureza e evolução histórica (Raicik \&, Peduzzi, 2015; Raposo, 2014; Rinaldi \&, Guerra, 2011). Defende-se a necessidade de um esforço centrado na interação entre ciência, cultura, sociedade e as visões de mundo de professores e estudantes e suas crenças metafísicas ou místicas, levando-os a refletir sobre essas diferenças (Matthews, 2009a; 2009b). Esse panorama é comum não apenas em nosso país, mas em vários países do mundo.

Argumenta-se que é responsabilidade dos cientistas e dos professores de ciências desmistificarem certas visões equivocadas sobre a natureza ciência. Epistemólogos contemporâneos apresentam diferentes posturas, às vezes divergentes, sobre esse tema, mas parece haver consenso entre os pesquisadores em ensino de ciências de que a discussão em sala de aula de aspectos da natureza da ciência pode promover reflexão crítica e diminuir o risco de se produzirem novas gerações de cidadãos que pensam que a ciência está além deles. Williams (1983), por exemplo, defendeu que a par da responsabilidade ser parte da vida em sociedade, a responsabilidade do cientista está acima daquela do cidadão comum, pois a sociedade custeia seu treinamento e os equipamentos necessários ao seu trabalho. Assim, o cientista possui uma responsabilidade adicional: ética e moral de divulgar os objetos de seu estudo devido à extensão dos efeitos de seu trabalho, de informar sobre o equilíbrio do mundo, a poluição dos oceanos, rios, o aquecimento global (Junges et al., 2018), sobre a extinção das espécies e de prevenir sobre os usos da ciência na guerra. Os professores de ciências devem integrar esse esforço, promovendo um ensino que inclua os objetos da ciência e algo sobre as ciências visando uma conscientização de sua implicação social.

Holt (2002), físico e congressista norte-americano, destacou a questão das representações sociais da ciência e advertiu que no Congresso americano, por exemplo, que é constituído por empresários, advogados, psicólogos, etc., há um desconforto com relação à ciência e à tecnologia, percebidas como algo misterioso, a que somente um grupo seleto tem acesso. Defendeu que um melhor entendimento da ciência, do trabalho dos cientistas, de seus procedimentos e objetivos pode evitar que os representantes da sociedade apoiem decisões errôneas sobre os usos da ciência.

Buscando diminuir o analfabetismo científico, surgiu na década de 1990, nos Estados Unidos, um movimento chamado Physics First sob o slogan da AAPT (American Association of Physics Teachers) de Physics for Al/ que pretende inverter a sequência Biologia-Química-Física (B-Q-F) passando-se a ensinar Física primeiro (F-Q-B). Promete um ensino de Física mais acessível, com o desenvolvimento de currículos apropriados e uma pedagogia mais efetiva, incluindo a qualificação dos professores de Física e a implementação de uma campanha de convencimento de que Física pode ser acessível para todos.

A proposta do presente estudo é discutir e refletir em que medida o movimento Physics First guarda, e se guarda, uma herança positivista em seus princípios mais fundamentais. Há que se destacar que por "positivismo" podemos entender uma ampla gama de variantes, pois este rótulo pode abranger diversas vertentes. No entanto, as nossas considerações críticas serão atinentes e mais centradas naquelas de lavra comtiana.

\section{O MOVIMENTO PHYSICS FIRST(PF)}

Physics First é um programa educacional que visa ressequenciar os cursos da escola secundária nos EUA para que os estudantes possam estudar Física antes de Química e Biologia. O objetivo é/era oferecer um curso básico de Física no nono grau - usualmente para estudantes de 15 anos 
de idade - em vez de Biologia que é mais comum nas escolas públicas americanas. O ponto fundamental é que com a sequência atual (B-Q-F) apenas em torno de $30 \%$ dos estudantes secundários americanos estudam Física. A preocupação dos educadores da National Science Foundation (NSF)e de muitos outros grupos é promover uma alfabetização científica para o cidadão e encorajar mais estudantes para as carreiras de ciências.

O ordenamento proposto pelo programa Physics First objetiva, assim, envolver mais estudantes nas disciplinas de ciências - física-química-biologia - que podem fornecer uma fundamentação para o entendimento de conceitos de Física e Engenharia e, ao mesmo tempo, promover uma conexão com conceitos de Matemática. As habilidades matemáticas exigidas pelo programa são limitadas, conhecimentos de álgebra, que permitem o estudo de cinemática, queda livre, leis do movimento de Newton, lei de Newton da gravidade, momentum, análise experimental e descrições qualitativas do movimento parabólico, máquinas simples, energia cinética e potencial, potência e trabalho, introdução da corrente elétrica e circuitos elétricos simples, e uma introdução qualitativa de magnetismo, ondas e espectro eletromagnético.

O movimento teve início, como referido, na década de 1990 e lentamente foi contagiando todo o país. O mais proeminente defensor do Physics First é Leon Max Lederman (1922), físico experimental e Premio Nobel em Física (1988) por seus trabalhos com neutrinos, Diretor Emérito do Fermi National Accelerator Laboratory (Fermilab), em Batavia, Illinois, USA.

Um breve histórico do ordenamento dos cursos de ciências nas escolas secundárias americanas, segundo Sheppard e Robbins (2003), mostra que o panorama no período 1890-2003 pode ser resumido da seguinte forma: em 1893 foi recomendado o ensino de Física antes da Química; em 1899 o sistema de créditos tornou obrigatório apenas uma ciência para admissão na universidade, o que fez da Física e da Química, disciplinas eletivas; em 1920 o Committee on Reorganization of Science in Secondary Schools recomendou a sequência Biologia-Química-Física (B-Q-F). Essa sequência tornou-se, após a segunda Guerra, o status quo nas escolas secundárias americanas e até os dias de hoje $99 \%$ delas a seguem. Com isso, a Física tornou-se uma disciplina eletiva como já mencionado, e apenas uma fração (aproximadamente $30 \%$ ) da população de estudantes se inscreve nela, de forma que muitos ingressam na universidade sem nunca terem estudado Física. Este declínio se manteve ao longo do séc. $X X$, com um pequeno aumento no final do século. Levantamentos da década de 1990 mostraram que o decréscimo nas matrículas em Física também esteve associado a outros fatores: os estudantes acham que a Física é muito abstrata, matematizada, sua aprendizagem muito dependente de livros de texto e os professores estão inadequadamente preparados (ibid.).

Em outros países, segundo Matthews (1995), foram implementadas algumas mudanças nos currículos escolares buscando reduzir o analfabetismo científico: na Holanda e Dinamarca incluíramse nos programa de ensino de ciências o item "a natureza da ciência"; na Inglaterra e País de Gales o Conselho Britânico de Currículo Nacional (NCC) defendeu, em 1988, a reformulação dos currículos de ensino fundamental e secundário sob o argumento de que os estudantes devem desenvolver seu conhecimento e entendimento sobre como o pensamento científico mudou através do tempo e como a natureza desse pensamento e sua utilização são afetados pelos contextos sociais, morais (...); nos EUA a Associação Americana para o Progresso da Ciência (AAAS) lançou, em 1989, um projeto incluindo tópicos sobre a natureza da ciência com esse mesmo objetivo. Com essas propostas, segundo o autor, esperava-se que as crianças considerassem o fato de que há perguntas 
a serem feitas e que comecem a refletir não somente sobre as respostas para essas perguntas, mas, sobretudo, sobre quais as respostas válidas. Ao longo das décadas obteve-se alguns sucessos e muitos fracassos desses programas, e o que se pôde aprender com os fracassos, segundo relatórios oficiais britânicos, é que os professores não estavam devidamente preparados para lidar com currículos contextualizados; que a transformação de projetos de currículos em realidades de sala de aula requer novas orientações para a prática e para a avaliação; que os professores não tinham conhecimentos adequados de História e Filosofia da Ciência e não conseguiam esclarecer para seus alunos os processos de idealização que a ciência utiliza, tentando evitar a construção de concepções ingênuas sobre os procedimentos da ciência.

Para Sheppard e Robbins (2009) o movimento Physics First pretendia suprir parte dessa lacuna, o analfabetismo científico; teve impulso nos EUA e tem sido assunto habitual nas Conferências de Professores de Física. A American Association of Physics Teachers-AAPT publicou em 2006 um guia do movimento (Physics First, 2006), além de um website que oferece um fórum para discussões. Destacam esses autores que a discussão não está mais restrita à Física, mas tem recebido apoio da American Chemical Society e de biólogos influentes. Adicionalmente, houve a apresentação, à época, de pelo menos seis teses de doutorado sobre o assunto, oferecendo mais subsídios ao movimento, cujo escopo é tornar a Física, seus conceitos e aspectos matemáticos associados, sua natureza e evolução histórica, acessível a todos os cidadãos.

Em 2002 a $A A P T$ adotou as seguintes posições em defesa do movimento PF: reconhecer que o ensino é uma importante forma de levar a Física para um número significativamente maior de estudantes do que aquele que ocorria costumeiramente nas escolas americanas; assumir que o $P F$ tem potencial para avançar mais substancialmente nas metas da AAPT de oferecer Physics for All e de implantar as fundações para cursos mais avançados em Física, Química e Biologia; reconhecer que o sucesso do programa dependia de necessárias ações específicas como, proceder à consulta entre administradores e professores para a escolha de um nível adequado do curso de Physics First, escolha essa que poderia ser conduzida pela familiaridade dos professores com as aptidões de seus estudantes; que era preciso desenvolver materiais e pedagogias apropriadas para alcançar a preparação matemática e o desenvolvimento cognitivo dos estudantes do $P F$, uma vez que são apreciavelmente mais jovens (têm em torno de 15 anos) do que os estudantes dos cursos de Física da escola secundária tradicional; propor que o nível, conteúdos e propostas do PF pudessem ser discutidos com os pais e outros membros da comunidade local; que houvesse provisão de treinamento e workshops para ajudar os professores a desenvolver e ensinar o PF de forma adequada.

Dessa maneira, a introdução do programa criava duas necessidades urgentes: uma, a elaboração de novos materiais - livros de texto, laboratórios, ferramentas, avaliação etc. - adequados aos estudantes do PF; outra, a necessidade de recrutar professores para ensinar no PFe oferecer-lhes suporte para habilitá-los e se sentirem confortáveis com os currículos do Physics First.

Adicionalmente, os professores das diferentes disciplinas precisariam trabalhar em conjunto e coordenar seus currículos com os de Física, de forma a haver uma integração dos currículos de Física, Química e Biologia.

Em suma, o PF dependia do desenvolvimento de materiais e estratégias de ensino úteis e potencialmente significativas, com especial atenção a uma cooperação e coordenação da Física 
com os cursos de Química e Biologia; do fomento para o desenvolvimento de workshops, treinamento e suporte para ajudar os professores de Física em todos os estágios de desenvolvimento de suas carreiras, sendo que particular atenção deveria ser dispensada ao encorajamento e assistência aos professores de outras disciplinas que estavam envolvidas com o ensino do Physics First.

Não se pretende assumir que o PF seria solução dos problemas antes apontados nos EUA, mas é importante lembrar que em nosso país a Base Nacional Comum Curricular (Brasil, 2017) prevê que sejam ensinados "objetos de conhecimento" relacionados à física desde os anos iniciais do Ensino Fundamental. Glasser (2012), em artigo publicado na Physics Teacher, afirma que mais escolas americanas começaram a ensinar física a estudantes do nono ano, mas que ainda há evidências limitadas de que a sequência invertida (física-química-biologia) beneficia os alunos; e adverte que muitos críticos afirmam que a mudança curricular baseia-se mais na lógica intelectual da sequência (fundamentos de física auxiliam o estudo da química, que favorece o estudo da biologia) do que em resultados medidos. Contudo, em seu estudo que enfoca a adoção do programa $P F$ em uma escola, Glasser sugere que a mudança impactou positivamente o desempenho matemático de estudantes em testes padronizados.

\section{APORTE TEÓRICO: POSITIVISMO DE AUGUSTE CONTE}

Em Os Pensadores - Comte (1988) pode-se encontrar o Curso de Filosofia Positiva de Auguste Comte, publicado em 1830. Esse curso iniciou em sua própria casa e foi frequentado por alguns dos maiores nomes da época como, por exemplo, o fisiólogo Henri-Marie de Blainville (1777-1850) e o psicólogo Jean-Étienne Esquirol (1772-1840). Na sua "Primeira Lição" Comte expõe o objetivo e natureza da filosofia positiva. Acredita ter descoberto uma lei fundamental segundo a qual as concepções principais de nossos conhecimentos passam sucessivamente por três estados históricos distintos: 0 estado teológico, o estado metafísico e o estado científico, ou positivo, nessa ordem.

No estado teológico o espírito humano dirige suas investigações para a natureza íntima dos seres, as causas primeiras e finais de todos os efeitos e busca entender os fenômenos como sendo o resultado da ação de agentes sobrenaturais. Nesse estado o número de observações é reduzido e a imaginação desempenha um papel importante. No estado metafísico, que é uma modificação do primeiro, os agentes sobrenaturais são substituídos por forças abstratas, entidades inerentes aos diversos seres do mundo e capazes, por si, de engendrar todos os fenômenos observados. No estado positivo o espírito humano reconhece a impossibilidade de se obter noções absolutas, renuncia à pretensão de conhecer as causas íntimas dos fenômenos para se preocupar em descobrir, através da combinação da observação e do raciocínio, suas leis efetivas, suas relações invariáveis.

Entendemos que Comte representava certo avanço em relação ao pensamento de Francis Bacon, fundador do método indutivo na ciência, ao afirmar que se repete desde Bacon, que somente são reais os conhecimentos que repousam sobre fatos observados. Essa máxima fundamental é evidentemente incontestável, se for aplicada, como convém, ao estado viril de nossa inteligência. Mas, reportando-se à formação de nossos conhecimentos (...) se de um lado toda teoria positiva deve necessariamente fundar-se sobre observações, é igualmente perceptível, de outro, que, para entregar-se à observação nosso espírito precisa de uma teoria qualquer. Se, contemplando os fenômenos, não nos vinculássemos de imediato a algum princípio, não apenas nos seria possível 
combinar essas observações isoladas, e por conseguinte, tirar daí algum fruto, mas seríamos inteiramente incapazes de retê-los (op. cit., p.5). O espírito humano, preso a um círculo vicioso entre a "necessidade de observar" para formar teorias gerais e a "necessidade de criar teorias" para poder observar, percebeu no desenvolvimento espontâneo das concepções teológicas, segundo Comte, uma porta natural aberta: nossa organização como seres humanos exigiu que essas filosofias primitivas (a teológica e a metafísica) funcionassem como estimulante indispensável para que o espírito humano se lançasse à investigação do mundo exterior e alcançasse a filosofia definitiva, a positiva. As ideias teológicas exageradas da importância do homem no universo, as atrativas quimeras da astrologia, as energéticas decepções da alquimia forneceram constância e ardor necessários para coletar longas séries de observações e experiências que serviram de fundamento para as primeiras teorias positivas.

Segundo Comte, a filosofia positiva, que seria o verdadeiro estado definitivo da inteligência humana, não deixou de precisar, no início e durante séculos, da filosofia teológica como doutrina provisória e da filosofia metafísica como doutrina transitória para a positiva, que se caracteriza pela subordinação da imaginação e da argumentação à observação e à experimentação. Com isso, Comte defende o empirismo puro, ou seja, a redução do conhecimento à apreensão de fatos e fenômenos isolados, mas não dispensou a razão.

Deve-se conceber o estudo da natureza, destinando-se a fornecer a verdadeira base racional da ação do homem sobre ela. O conhecimento das leis e fenômenos, cujo resultado constante é fazer com que sejam previstos por nós, evidentemente pode nos conduzir, de modo exclusivo, na vida ativa, a modificar um fenômeno por outro, tudo isso em nosso proveito. (...). Ciência, daí previdência; previdência, daí ação (Comte, 1988, p. 23).

Objeto central do curso de Comte, a filosofia positiva, tem por fim abandonar a imaginação dos teólogos e a sutileza dos metafísicos e tomar os fenômenos, fundamentalmente sujeitos a leis naturais invariáveis, cuja descoberta precisa de redução a seu menor número possível constitui o propósito de todos os nossos esforços. Fica inacessível e vazia de sentido a investigação das chamadas "causas", sejam primeiras ou finais. Como exemplo, cita as pesquisas de Fourier, de caráter positivo, sobre o calor e afirma que as leis mais importantes e precisas dos fenômenos termológicos foram desvendadas sem que Fourier tenha inquirido sobre a natureza íntima do calor.

Destacou Comte que os diferentes ramos do conhecimento não percorreram com igual velocidade as três fases antes indicadas. Existe a esse respeito uma ordem invariável e necessária que os diferentes ramos e gêneros tiveram de seguir em sua progressão e que está associada à natureza distinta dos fenômenos, ao grau de generalidade, de simplicidade e de independência recíprocas.

Considerou os fenômenos astronômicos como os mais gerais, simples e independentes e sucessivamente os fenômenos da Física terrestre, depois os da Química e por fim os fisiológicos. Destacou, contudo, essas quatro categorias apresentam uma lacuna essencial, relativa aos fenômenos sociais que, por sua importância e dificuldades próprias para seu estudo, merecem uma categoria distinta. Foi essa lacuna que Comte procurou preencher com sua física social que completaria, dessa forma, o sistema das ciências naturais (ibid., p. 10)

Primitivamente, advertiu Comte, os trabalhos intelectuais não exigiram nenhuma divisão, mas à medida que se desenvolveu cada ramo da ciência, por necessidade, se separou do tronco. A divisão do trabalho intelectual, aperfeiçoada progressivamente, é um dos atributos característicos mais importantes da filosofia positiva (p. 11). Contudo, Comte também alertou para os inconvenientes da 
excessiva particularização das ideias, da especialização exagerada das pesquisas e defendeu o surgimento de uma nova especialidade, uma nova classe de cientistas, incessantemente controlada por todas as demais, que se ocupasse com o estudo das generalidades, em descobrir as relações entre as diversas ciências positivas, em resumir seus princípios num número menor de princípios comuns. As vantagens desse trabalho seria fornecer um meio racional de pôr em evidência as leis lógicas do espírito humano.

O primeiro grande resultado da filosofia positiva foi, para o Comte, a manifestação pela experiência das leis, ou seja, ciência resulta da investigação do real. Uma segunda consequência foi presidir, segundo esse pensador, uma reforma geral do sistema da educação europeia, substituindo-se a educação teológica, metafísica e literária pela educação racional, que exige um conjunto de concepções positivas sobre todas as classes de fenômenos naturais.

$\mathrm{Na}$ "Segunda Lição" Comte argumenta que é necessário determinar uma classificação racional conveniente entre as diferentes ciências positivas a fim de estudá-las. A classificação deve ser tratada pela observação em vez de ser resolvida por considerações a priori, ou seja, a classificação deve provir do próprio estudo dos objetos a serem classificados, sendo determinada pelas afinidades reais do encadeamento natural apresentado por eles (p. 22).

Tal classificação estrutura-se em torno de três pontos básicos: primeiro, uma filosofia da história com o objetivo de mostrar as razões pelas quais certa maneira de pensar - o pensamento positivo - deve imperar entre os seres humanos; segundo, uma fundamentação e classificação das ciências baseada no positivismo; terceiro, uma sociologia que, determinando a estrutura e os processos de modificação da sociedade, permitisse a reforma prática das instituições.

Uma divisão geral de nossos conhecimentos consiste em distingui-los em teóricos e práticos. Os conhecimentos teóricos são os que tratam das concepções mais fundamentais sobre as diversas ordens dos fenômenos que fornecem uma base sólida para o sistema intelectual. Os conhecimentos práticos devem ser considerados tão somente para esclarecer o conhecimento teórico, pois se o espírito dos cientistas se ocupasse apenas com investigações suscetíveis de utilidade prática imediata a ciência seria privada de seu progresso, segundo Comte. As aplicações mais importantes derivam de teorias formuladas com simples intenção científica. Muitas vezes essas teorias se estenderam por séculos sem nenhum resultado prático. Como exemplo, cita as teorias dos geômetras gregos que através de uma série de gerações determinaram uma renovação da astronomia que ao final conduziu ao aperfeiçoamento da arte da navegação.

Segundo Comte, se considerarmos todos os fenômenos observáveis é possível classificá-los num pequeno número de categorias naturais de tal forma que o estudo racional de uma dada categoria se converte no fundamento do estudo da seguinte. Essa ordem é determinada pelo grau de simplicidade e de generalidade dos fenômenos.

Os fenômenos mais simples são necessariamente os mais gerais e é deles que se começa o estudo, procedendo sucessivamente até os fenômenos mais particulares e mais complexos. O encadeamento racional das diferentes ciências fundamentais é determinado pela dependência sucessiva de seus fenômenos. Há duas grandes classes de fenômenos segundo esse princípio, a dos fenômenos dos corpos brutos ou inorgânicos e a dos fenômenos dos corpos organizados (os seres vivos). Estes últimos são mais complicados e particulares e dependem dos primeiros, daí a necessidade de estudar 
os fenômenos fisiológicos depois dos fenômenos dos corpos brutos. Nos corpos vivos se observam todos os fenômenos, sejam mecânicos, elétricos e químicos, que têm lugar nos corpos brutos, acrescidos dos fenômenos vitais propriamente ditos, que dizem respeito à auto-organização.

Supondo que os fenômenos fisiológicos sejam fenômenos químicos, elétricos e mecânicos modificados pela estrutura dos corpos organizados, então os fenômenos mais gerais devem ser estudados antes de se proceder ao exame das modificações especiais que sofrem nos seres vivos, em virtude de uma disposição particular das moléculas.

Como resultado dessa discussão, e segundo a filosofia positiva, há uma importante hierarquia das cinco ciências fundamentais, cuja sucessão é determinada pela subordinação, necessária e invariável, dos fenômenos correspondentes, a saber: a astronomia, a física, a química, e fisiologia (ou biologia) e a física social (ibid., p. 33).

A astronomia deve começar o estudo da filosofia natural, pois trata de fenômenos mais gerais, mais simples, e as leis aos quais estão sujeitos influenciam as leis de todos os demais fenômenos, mas sendo essencialmente independentes destas últimas. Em todos os fenômenos físicos terrestres observam-se os efeitos da gravitação universal, acrescidos de outros efeitos que lhe são próprios. Os fenômenos químicos são mais complicados que os fenômenos físicos. Dependem da gravidade, do calor, da eletricidade, etc., e apresentam alguma coisa de próprio que os modificam ${ }^{3}$. A Química supõe o conhecimento prévio da Física. A Biologia, estudo dos seres vivos, é mais complexa e depende dos precedentes, sem os influenciar. A última ordem, a dos fenômenos sociais, é a mais complicada e mais particular, todos os fenômenos sociais são influenciados pelas leis fisiológicas dos indivíduos e resultam da ação dos indivíduos uns sobre os outros e, em particular na espécie humana, da ação de cada geração sobre aquela que se segue.

Por esses argumentos, a classificação positivista hierárquica das ciências vai do mais simples e mais geral na direção do mais complexo e mais particular.

É importante ressaltar que Comte faz ainda uma espécie de refinamento em sua classificação das ciências. Ele escreve:

\begin{abstract}
Vê-se que os fenômenos geométricos e mecânicos são, entre todos, os mais gerais, os mais simples, os mais abstratos e mais irredutíveis e os mais independentes de todos os outros [...]. Concebe-se paralelamente que seu estudo seja preliminar indispensável ao estudo de todas as outras ordens de fenômenos. A ciência matemática deve, pois, constituir o verdadeiro ponto de partida de toda educação científica racional $[\ldots]$ (COMTE, p. 39).
\end{abstract}

Deste modo, a nova classificação passa a incluir a matemática e segue rigorosamente esta ordem: matemática, astronomia, física, química, fisiologia e física social. Trata-se de uma ordem que vai dos fenômenos mais simples, gerais e irredutíveis àqueles que são gradativamente mais complexos, menos gerais e mais redutíveis. Essa classificação, como veremos, terá enorme repercussão no Programa Educacional, nas concepções de Ensino da era industrial e das demandas

\footnotetext{
${ }^{3} \mathrm{Em}$ manuais didáticos mais antigos, mas não totalmente fora de circulação, pode-se encontrar uma caracterização diferenciadora entre física e química como a seguinte: os fenômenos físicos seriam aqueles nos quais não houvesse mudança na sua estrutura íntima enquanto os fenômenos químicos seriam aqueles nos quais houvesse tais mudanças. Bem entendido, isso não se aplica aos fenômenos estudados na ciência do século XX tais como aqueles da física nuclear (elementos transurânicos e a radioatividade) nos quais a estrutura íntima da matéria é alterada. É importante lembrar que Comte se atém à ciência do século XIX.
} 
de uma rigorosa e crescente divisão social do trabalho. Não apenas isso como também Comte se refere a expressões apologéticas como Regeneração da Europa e Regeneração do Ocidente.

\section{PHYSICS FIRST VERSUS POSITIVISMO: UMA DISCUSSÃO}

Uma reflexão mais aprofundada dos argumentos em defesa do movimento contemporâneo Physics First sugere que existem vários pontos comuns com a filosofia positivista de Comte, como abordada no item precedente de forma que cabe a pergunta: o PFrepresentaria uma herança positivista? E se assim for, em que medida pode ser entendida como uma herança maldita?

Não é incomum se encontrar na literatura achados que sugerem heranças positivistas no ensino/aprendizagem de ciências. Costa e Domènech (2002), por exemplo, ao pesquisar as concepções epistemológicas nas práticas educativas de professores de ciências identificaram uma forte concepção positivista, em que tecnologia é entendida como um campo derivado da ciência com ênfase no produto, presente nas práticas didáticas desses professores. Ogunniyi (1982) investigou as concepções epistemológicas de futuros professores de ciências e concluiu que eles apresentavam pontos de vista, com respeito à linguagem da ciência, próximos aos de Hempel (lógico-positivista), com noções indutivas da natureza da ciência. Guisasola e Morentin (2007), em investigação sobre as concepções de futuros professores do ensino básico espanhol com respeito aos objetivos, metodologia e evolução do conhecimento científico, obtiveram, através de um questionário de perguntas abertas, que a maioria dos futuros professores apresentava uma concepção positivista da ciência, entendendo-a como um corpo de conhecimentos formado por fenômenos naturais e teorias verdadeiras e comprovadas pelos dados observacionais ( $71 \%$ dos entrevistados); que os fatos científicos dão significado às teorias e que a observação e detecção de fenômenos é a parte mais importante da metodologia científica ( $90 \%$ dos entrevistados). Em tese de doutorado que investigou a presença e a contribuição de diferentes posturas epistemológicas contemporâneas nas práticas docentes de professores de Física no Ensino Médio (Massoni, 2010) obteve-se que as visões dos estudantes de Ensino Médio são bastante ingênuas, associadas a descobertas de teorias físicas através do uso rigoroso do "método científico" algorítmico e que os professores de Física investigados, mesmo aqueles que tiveram em sua formação uma introdução à Epistemologia Contemporânea, não fazem uso das novas posturas de forma explícita e acabam transmitindo, em geral, uma visão rígida e bastante positivista sobre a natureza da Física.

Destaca-se que as posturas epistemológicas contemporâneas constituem uma nova maneira de conceber a natureza da ciência, seus variados métodos e sua evolução histórica. Através delas passou-se a defender, em grandes linhas, que: a ciência é uma construção humana; que conhecimento científico não nasce da observação pura, pois toda observação está carregada de pressupostos teóricos; que as leis e teorias da Física, e da ciência em geral, têm natureza hipotética, conjetural, e que as hipóteses são verificadas experimentalmente em alguma medida; que as leis e teorias não são verdades fixas e imutáveis, mas são aceitas provisoriamente pela comunidade científica até que surjam novas e melhores explicações, com maior capacidade preditiva; que conceitos, leis, teorias e modelos científicos evoluem com o avanço da ciência e tecnologia; que o conhecimento científico não é linear e acumulativo, mas é marcado por controvérsias, erros e retificações; que elementos não racionais como imaginação, criatividade e intuição fazem parte do processo da ciência e não existe um "método científico" universal, ahistórico e algorítmico para se fazer ciência, ao contrário, distintos procedimentos metodológicos podem estar implícitos em 
diferentes ramos da ciência; há competição entre teorias e programas de pesquisa nos mais diversos campos da ciência; que aspirações pessoais dos cientistas e o contexto sócio-político-cultural interferem na ciência de forma importante e, portanto, a ciência não é neutra; as comunidades cientificas, os periódicos, os congressos e encontros estimulam e ao mesmo tempo filtram novas ideias científicas; a instrumentação e a técnica são fundamentais para a criação de novos fatos e para o avanço da ciência.

Assim, pode-se dizer que com respeito à natureza da ciência as ideias positivistas se mostram ultrapassadas e superadas frente o debate epistemológico contemporâneo. Contudo, o mesmo, eventualmente, não se pode afirmar com relação ao ordenamento ou classificação para o estudo das ciências mais fundamentais. O movimento Physics First que tem contagiado os EUA é um exemplo de que muitas ideias positivistas sobre o grau de generalidade e simplicidade das diversas ciências e sobre uma possível hierarquia para seu estudo pode ser bastante atual.

Uma visualização mais clara dessas eventuais semelhanças pode ser observada no Quadro 1.

Quadro 1: Recortes de textos (Lederman, 2005 e do Guia do Physics First) que mostram algumas semelhanças com as ideias de Comte, em seu Curso de Filosofia Positiva.

\section{PRINCIPAIS ARGUMENTOS EM FAVOR DO MOVIMENTO PHYSICS FIRST \\ Lederman (2005) destaca que a maior virtude da sequência Física-Química-Biologia é a natureza hierárquica das ciências em conjunto com 0 desenvolvimento de habilidades matemáticas. Física pode vir primeiro, argumenta, porque é um excelente pré- requisito para a Química. O estudo dos átomos e dos princípios básicos da estrutura atômica na Física facilita uma coerente sequência da Química que faz uso dessa estrutura atômica e fornece leis, a tabela periódica, o comportamento dos elementos químicos e a formação de moléculas. Por sua vez, 0 comportamento das moléculas complexas é crucial para a Biologia molecular. Adicionalmente, defende que parte do conteúdo dessas disciplinas, em torno de $20 \%$, deve ser substituído pela história de como a ciência e os cientistas trabalham, com vistas a ensinar o cidadão a ser mais crítico e reflexivo.}

A $A A P T$ no Guia do Physics First (2006, p.4/5) afirma que se a sequência de instrução é iniciada de forma que a Física ofereça uma fundamentação para Química ou Biologia, a ênfase nos tópicos oferece várias vantagens (...) um entendimento conceitual em vez de manipulação matemática.

A preocupação de educadores americanos é: 1) para entender a moderna Biologia molecular e os processos químicos nas células, o estudantes necessitam de uma sólida formação em Física e Química; 2) o domínio de conceitos físicos básicos em eletrostática, das forças nucleares, dos conceitos de armazenamento e transferência de energia são cruciais para o entendimento das estruturas químicas, das ligações atômicas, das leis dos gases e da tabela periódica dos elementos.

\section{ARGUMENTOS POSITIVISTAS CLASSIFICAÇÃO DAS CIÊNCIAS}

Todos os fenômenos observáveis podem ser classificados num pequeno número de categorias naturais, dispostas de tal maneira que $o$ estudo racional de cada categoria funde-se no conhecimento das leis principais da categoria precedente, convertendo-se no fundamento do estudo seguinte. Essa ordem é determinada pelo grau de simplicidade ou, o que vale o mesmo, pelo grau de generalidade dos fenômenos (Comte, p. 30).

Como resultado dessa discussão, a filosofia positiva se encontra, pois naturalmente dividida em cinco ciências fundamentais, cuja sucessão é determinada pela subordinação necessária e invariável, fundada, independentemente de toda opinião hipotética, na simples comparação aprofundada dos fenômenos correspondentes: a astronomia, a física, a química, a fisiologia (Biologia)e, enfim, a física social. A primeira considera os fenômenos mais gerais, mais simples, mas abstratos e mais afastados da humanidade, $e$ que influenciam todos os outros sem serem influenciados por estes. Os fenômenos considerados pela última são, ao contrário, os mais particulares, mais complicados (...) (ibid., p. 33). 
Seria adequado supor uma impossibilidade de convivência entre alguns princípios positivistas de ordenamento das ciências e os valores e argumentos norte-americanos que embasam o movimento Physics First? Por que esse movimento se dá nos EUA e não em outro país do mundo?

Possivelmente, para abordar essas questões de forma mais aprofundada, seja importante fazer algumas considerações históricas e culturais a respeito dos Estados Unidos da América. Karnal et al. (2010) ensinam que são complexos e diversos os motivos por que os EUA, considerado um centro de decisões mundiais, é um país diferenciado, que desperta muitos e dicotômicos sentimentos em todas partes do mundo. Um país de desenvolvimento tecnológico e industrial incomparável, que espalhou ao mundo o cinema e o jazz, que incorpora cientistas do mundo todo, uma nação considerada sem Deus e que ao mesmo tem numerosas escolas que negam o evolucionismo e defendem o ensino do design inteligente ${ }^{4}$, razão segundo os autores, entre outras, por que os olhares se voltam para ele com sentimentos tão dicotômicos. Nenhum outro país parece ter recebido tantos observadores $e$ tantos imigrantes como os Estados Unidos da América (ibid., p. 14) nos últimos 200 anos. A explicação mais usual é que há dois Estados Unidos da América, um crítico e aberto e outro tradicional e fechado. Mas esta é uma explicação insuficiente. Há outras como, por exemplo, que o elemento definidor do sucesso norte-americano nas suas origens foi sua geografia, suas planícies, seus rios excelentes para navegação que facilitaram em muito o trabalho dos colonizadores; que a postura colonizadora protestante, particularmente dos calvinistas, via o trabalho, a poupança, o dinheiro como sinais externos da "graça divina" ao contrário das colonizações ibéricas, católicas, que viam o progresso econômico com desconfiança; que as diferenças entre a América saxônica e a ibérica foram resultados de escolhas políticas e culturais; que as colônias ibéricas eram mais metódicas enquanto as 13 colônias que formaram os EUA nasceram sem a tutela direta do Estado e aproximaram-se mais rapidamente de sua independência; que os colonizadores ingleses vieram para a América trazendo uma tradição cultural diversa, o convívio com diversas religiões, traços que ajudaram a formar 0 senso do relativo e uma visão de mundo mais diversificada.

Especialmente as causas religiosas trouxeram para a América pessoas instruídas em busca de liberdade religiosa e de novas terras. Eram peregrinos e não infratores. Ao chegarem às terras do atual EUA depararam-se com invernos mais rigorosos que os da Inglaterra, enfrentaram inúmeras dificuldades que, sem a proteção do Estado e expostos à própria sorte, levou-os a construir um sentido de união pela sobrevivência, um espírito empreendedor que resultou no sentimento de nação e de desenvolvimento sem precedentes.

Contudo, não é, certamente, nessas explicações simplistas de povoamento e exploração que encontraremos respostas para tão gritantes diferenças na América. Essa breve introdução oferece apenas algumas ideias para uma melhor compreensão de como um país de tão exuberante crescimento econômico, científico e tecnológico, marcado por feitos de um povo persistente conserva, ao mesmo tempo, certo provincianismo e uma invisibilidade para com os povos externos.

Do ponto de vista do ensino de ciências as coisas não parecem muito diferentes. Os norte-americanos podem ser, em certos aspectos, mais conservadores do que se poderia imaginar e as bases do movimento contemporâneo Physics First sugerem certas heranças positivistas, como já mencionado.

\footnotetext{
${ }^{4}$ Forma moderna de criacionismo, que afirma que a dinâmica e as características da natureza são atribuídas a uma causa inteligente. O Design Inteligente não é aceito pela comunidade científica, sequer como merecedor de investigação.
} 
A sequência de ensino de ciências, biologia-química-física, foi recomendada em 1893 e se tornou comum nas escolas secundárias americanas e em 1899 o sistema de créditos - que tornou obrigatória apenas uma ciência para admissão à universidade - acabou por transformar a Física e a Química em disciplinas eletivas e cada vez menos estudantes passaram e se inscrever nelas. Essa situação contribuiu para o alto índice de analfabetismo científico que tem preocupado os educadores naquele país.

Diante dessa situação, Associações de educadores passaram a defender um ressequenciamento física-química-biologia - que, em boa medida, pode ser entendido como uma forma de engajar mais estudantes nas disciplinas de ciências, para quem os conceitos da Física podem fornecer uma base para o entendimento dos conceitos da Química e esta àqueles mais específicos da Biologia.

Assim, os fundamentos do movimento Physics First parecem apresentar como ideia subjacente a hierarquia entre as ciências fundamentais que é um elemento tipicamente positivista. Argumenta-se que começando com um curso de Física, os estudantes exploram suas próprias noções sobre os fenômenos quotidianos, discutem suas observações e tiram conclusões que podem ser testadas, começam a fazer predições, praticam técnicas de coleta de dados, de construção de gráficos, aplicam algumas habilidades matemáticas para situações reais e começam a dar sentido a suas observações.

O foco na compreensão conceitual da Física como base para melhor compreender a Química e a Biologia sob o argumento de que os fundamentos da Física podem ser ensinados sem um grau elevado de Matemática ${ }^{5}$, parece guardar uma herança positivista que, possivelmente, tem a ver com certo conservadorismo norte-americano.

Seja como for, há que se refletir se de fato essa herança positivista pode ser entendida como uma influência nefasta?

Não parece ser assim quando se leva em consideração o contexto em que se dá o movimento Physics First nos EUA. Em que pesem as críticas dos epistemólogos contemporâneos à filosofia positivista com relação à natureza da ciência, com as quais concordamos, não é possível desconhecer que a observação e a indução tomam parte da ciência de forma importante, mas não apenas elas. Além disso, as ideias de Comte em relação a um ordenamento hierárquico das ciências parecem bastante atuais e razoáveis: estudar os átomos, seus constituintes, suas interações e assim compreender os diferentes tipos de substâncias, as ligações químicas, a tabela periódica dos elementos e então avançar para a Biologia, que envolve cadeias e moléculas complexas, inerentes aos corpos organizados (a vida), parece um sequenciamento racional razoável.

E, como bem advertem alguns pesquisadores em Ensino de Física, se é responsabilidade dos cientistas e dos educadores reverterem o quadro atual de analfabetismo científico, de ausência de criticidade em relação às ciências, de persistência de visões inadequadas da natureza da ciência amplamente veiculadas pela mídia e reproduzidas na escola, não há motivos plausíveis para

\footnotetext{
${ }^{5}$ Há considerável controvérsia com relação a este ponto. Penrose, por exemplo, se manifestou claramente contrário a um ensino e a uma divulgação da Física no contexto de uma espécie de "desmatematização" dos conteúdos. A despeito da advertência dos editores de que carregar o seu livro The Road of Reality com matemática seria motivo de afastamento de eventuais leitores, Penrose não traiu as suas conviç̧ões ao asseverar que "não podemos ter uma compreensão profunda das leis que regem o mundo físico sem entrar no mundo das matemáticas" (Penrose, 2008, Prefácio, p. 26). Ele levou tão a sério essa orientação que dedicou os 16 primeiros capítulos de seu livro, que contém um total de 34 capítulos, a uma exposição e a uma descrição das ideias matemáticas que considerou como fundamentais para a compreensão da Física.
} 
considerar que a herança positivista seja tão maldita, no que tange aos aspectos aqui considerados, afinal ela é, como dito, parte da nossa herança.

\section{O PROGRAMA EDUCACIONAL DO POSITIVISMO}

A avaliação de uma eventual ou real herança positivista de lavra comtiana no movimento Physics First não deve ser demonizada, como aliás, e infelizmente, vem se constituindo quase toda a crítica dirigida às possíveis influências positivistas as quais, quase que imediata e preconceituosamente, são taxadas como necessariamente más. Satanizar a priorio positivismo constitui-se em um gravíssimo equívoco. Por mais que a crítica ao positivismo e ao empirismo seja consubstanciada e pertinente, para ser consequente ela não deverá proceder de tal maneira a recusar a priori a influência dessa corrente de pensamento como sendo necessariamente algo nocivo. Isso porque há também argumentos de natureza educacional e de natureza epistemológica que podem ser aduzidos em prol de alguns aspectos relevantes e importantes do positivismo.

Se o caráter acético do positivismo que pretendia varrer todos os resquícios teológico-metafísicos das teorias científicas bem como a sua ultrapassada concepção linear de história e ainda a sua insistência em um método indutivo revelaram-se como sendo insustentáveis diante das posturas epistemológicas contemporâneas, nem por isso a sua tão criticada noção de progresso associado ao pressuposto estágio positivo (científico) e com este as necessidades de demanda de uma crescente divisão intelectual e social do trabalho ensejadas por um mundo cada vez mais científico, tecnológico e industrial devem ser desconsideradas. Não é sem razão que a própria classificação nos três estágios de evolução da humanidade aliada à classificação hierarquizada das ciências em ordem crescente de simplicidade constituía a pedra angular da filosofia subjacente que orientaria a Reforma Educacional.

Comte pretendia instaurar uma nova concepção de educação científica. No estágio positivo, deveria prevalecer aquilo que ele próprio chamou de educação dogmática ao invés de uma educação histórica (Comte, p. 27, 1988).

A educação dogmática consistia em um programa de 'queimar etapas'. Em outras palavras, complexos desenvolvimentos cognitivos que uma sucessão de espíritos dedicados e persistentes demandou séculos para empreender e para compreender, deveriam ser compreendidos, mediante uma sistematização simplificadora, por espíritos cognoscentes e em muito menor espaço de tempo. Contrapunha-se a essa educação dogmática uma educação histórica que submetia normais cidadãos à perplexidade desafiadora de se verem imersos nas complexas construções do pensamento, nas imensas controvérsias inclusive aquelas com intenso teor teológico-metafísico, o que segundo Comte, demandaria um tempo exagerado e totalmente inócuo, o que seria absolutamente incompatível com o espírito positivo e com a filosofia positiva. Em outras palavras, as demandas de uma educação dogmática eram fundamentais para a consecução de uma divisão de trabalho compatível com o espírito positivo. Essa concepção teve grande repercussão na França a partir de meados do século XIX e também influenciou de maneira bastante relevante a educação científica brasileira dos séculos XIX e XX através dos manuais franceses que foram tomados como base para o ensino das ciências (Braga, Guerra, Reis, 2008).

Essa concepção de educação ensejada pela filosofia positiva estava conectada - no que concerne aos planos, respectivamente metodológico e epistemológico - com uma classificação hierárquica das ciências tomando por base os graus crescentes de dificuldade dessas que começaria com a 
matemática para depois ir à astronomia, à física, à química, à fisiologia para então culminar na física social que seria a ciência de maior grau de complexidade. Comte é considerado o criador da física social, hoje bastante distanciada de seu proponente e mais aceita como sociologia.

Os planos respectivamente, educacional, metodológico e epistemológico se conectariam de tal maneira a melhor propiciar a eficiência da educação dogmática a qual deveria se coadunar com essa ordem hierárquica de dificuldades.

No início do séc. XXI, não apenas o movimento Physics First e o seu slogan Physics for All, mas educadores também clamavam pela necessidade de que os cidadãos do país mais industrializado do mundo superassem, ainda que parcialmente, o seu considerável grau de analfabetismo científico. Além da ideia de que a Física precisa ser ensinada antes das outras ciências naturais em razão de uma ordem que estaria implícita na própria natureza, há também várias teorias da aprendizagem que reivindicam atalhos cognitivos os quais, podemos considerar que estejam bem próximos da recomendação comtiana em prol da educação dogmática e em detrimento de uma praticamente impossível educação histórica se levada ao completo radicalismo ${ }^{6}$. E isso se reforça sobremaneira se viermos a considerar o ensino em grande escala. Decerto, há o argumento, aliás muito pertinente, segundo o qual o que fortalece o movimento Physics First é que o nível das interações básicas entre átomos pertence a uma ordem da natureza que, no plano pedagógico, deve preceder ao estudo do nível molecular e esse deve preceder ao nível celular e assim por diante. No entanto, não se deve desconsiderar também a razão da necessidade de atalhos ${ }^{7}$ a fim de se cumprir as exigências da educação dogmática e com esta também a exigência de uma estrutura curricular contendo prérequisitos e tudo isso como decorrência de uma crescente divisão intelectual e social do trabalho. Vejamos por quê.

Ora, a própria teoria da transposição didática (Chevallard, 1991; Brockington \& Pietrocola, 2005) reconhece que o saber sábio difere do saber contido nos livros didáticose esses, por sua vez, também diferem substancialmente do saber ensinado. Podemos ainda aduzir que esse saber efetivamente ensinado ainda passa por outras transposições em nível de interpretações várias por parte dos sujeitos cognoscentes e aqui não estamos considerando o nível das percepções subjetivas. Estamos supondo que certo saber objetivo passa por todas essas instâncias de transposição sem que venha a sofrer alterações que sejam substantivas do seu teor. Em outras palavras, espera-se, por exemplo, que as várias instâncias de transposições não modifiquem o cerne das leis de Newton originais.

Perseguindo o nosso objetivo de obter uma resposta mais instrutiva, ainda que seja parcial, para a eventual ou real herança positivista no movimento Physics First argumentaremos sobre a conexão entre os planos pedagógico e epistemológico do programa positivista bem como a crítica desta visão

\footnotetext{
${ }^{6}$ Comte admite um ensino de ciências que seja uma combinação desses dois caminhos distintos. Ele asseverou: "Toda a ciência pode ser exposta mediante dois caminhos essencialmente distintos: o caminho histórico e o caminho dogmático. Qualquer outro caminho não será mais do que sua combinação." (COMTE, 1988, p. 27).

${ }^{7}$ Não se deve reduzir a necessidade de atalhos apenas a uma demanda do positivismo de Comte. A descrição kuhniana de ciência normal inclui necessariamente uma disciplina paradigmática baseada em livros textos e currículos que servirão de treinamento dogmático (segundo as próprias palavras de Kuhn) para o exercício da própria ciência normal, período que se segue a uma Revolução Científica, em que não se está em busca propriamente de novidades científicas, mas sim de consolidação da nova ordem científica. Popper criticou severamente a ciência normal. Ele admitiu que embora ela de fato exista, constitui degradação do pensamento e como tal tem que ser combatida.
} 
à luz de desenvolvimentos mais recentes. Alguns dos aspectos das controvérsias ensejadas por adoções filosóficas conflitantes também serão aqui comentados.

\section{DA CONEXÃO ENTRE OS PLANOS PEDAGÓGICOS E EPISTEMOLÓGICOS}

Seguramente, seria algo inusitado e raríssimo que alguém recomendasse para um adolescente do século XXI que aprendesse a geometria euclidiana lendo extensivamente a obra de Euclides, que estudasse as leis de Newton pela leitura atenta e judiciosa dos Principia, que estudasse eletromagnetismo lendo diretamente a obra de Maxwell e que estudasse como Galileu chegou ao resultado dos movimentos parabólicos ao ler detalhadamente os Discorsie a partir daí acompanhasse como o sábio florentino houvera feito uso do tratado das seções cônicas de Apolônio de Perga. Sem dúvida, tudo isso seria de pouquíssima eficácia em um ensino corrente para um público abrangente, embora pudesse sensibilizar estudantes muito especiais. Mesmo que fosse algo viável de ser implantado em um ensino de larga escala, assim procedendo muito dificilmente os teores visitados seriam minimamente entendidos para a esmagadora maioria dos estudantes. No entanto, há reconstruções racionais sistematizadas que constituem atalhos de boa qualidade mediante os quais os princípios da geometria e seus teoremas, as leis de Newton, as leis de Maxwell e o movimento parabólico de Galileu podem ser razoavelmente bem entendidos com um esforço compatível com o tempo e o nível intelectual e cultural do adolescente, bem como do correspondente nível de seu professor. Logo, a recomendação do que Comte entendeu por educação dogmática em detrimento da educação histórica e a recomendação muito posterior de que transposições didáticas sejam, de fato, necessárias em quaisquer que sejam os sistemas educacionais são ambas bastante pertinentes. No caso do movimento parabólico de Galileu, a abordagem habitual em sala de aula é a de demonstrar que, a partir das equações em geometria analítica correspondentes respectivamente aos movimentos com velocidade constante em $x$ e com aceleração constante em y, podemos concluir, admitindo a independência e a composição dos movimentos e eliminando o tempo das equações, que a trajetória resultante é parabólica. Esta abordagem habitual é, pois, uma reconstrução racional. De fato, não foi esta a maneira como Galileu procedeu, mesmo porque ele não usou a geometria analítica e sim a geometria dos gregos. Um ensino de Física consequentemente pode lançar mão de uma abordagem que não seja a histórica, e sim a ensejada por uma simplificação legítima que preserve o conteúdo correspondente. E para evitar cair naquilo que os historiadores da ciência chamam de anacronismo (se ater a explicações de episódios históricos com conceitos que não existiam na época nem que foram usados por aqueles autores) basta que nos atenhamos à reconstrução racional e façamos alusão à maneira histórica. Para tal, devemos situar o problema/episódio analisado para nos colocar atentos aos riscos do anacronismo. Esta é no fundo a recomendação de Lakatos quando asseverou que um episódio da história da ciência deveria ser analisado tanto de uma maneira histórica quanto mediante o uso de reconstruções racionais; dever-se-ia criticar severamente tanto a "falta de racionalidade" do caminho histórico quanto a "falta de historicidade" da reconstrução racional e, após isso, confrontá-las. A História e Filosofia da Ciência que interessa aos professores de Física e de outras ciências é muito mais aquela ensejada por reconstruções racionais atentas aos perigos do anacronismo (que, de fato, constitui um risco permanente) e não aquela no viés do historiador da ciência cioso da pesquisa em arquivo e com os métodos rigorosos da historiografia. Bem entendido, a pesquisa no viés do historiador é de alta relevância e grande importância, mas sua aplicação no contexto do Ensino de Ciências é, eventualmente, de pouca viabilidade concreta por razões análogas às aventadas por Comte. 
Bem entendido, a história no viés do historiador é muitíssimo bem vinda enquanto subsídio importante ao professor de ciências, e em especial ao professor de Física, mas seu foco não deverá ser, salvo em situações especiais, aquele que segue os métodos da historiografia, pois se assim o fosse o próprio Ensino de Ciências poderia muito facilmente se dispersar e se desvirtuar. Em suma, o professor de ciências deve usar criticamente e dentro a sua autonomia, qual o tipo de História e Filosofia da Ciência que mais convém à sua prática didática e isso é um desafio permanente em qualquer situação que seja. Desnecessário, mais uma vez, afirmar a relevância de Comte ao ressaltar a inviabilidade da educação histórica quando levada a extremos.

Há de fato situações análogas entre a educação dogmática em contraposição à educação histórica, entre o saber sábio em contraposição ao saber ensinado (Chevallard, 1991), entre a reconstrução racional em contraposição à história "real", e entre o contexto da justificação em contraposição ao contexto da descoberta. Sem dúvida, linhas demarcatórias rigorosas são difíceis de serem traçadas, pois, por exemplo, poderíamos perguntar o que seria de fato uma história "real" se toda história constitui-se em interpretação de fatos escolhidos à luz de quadros referenciais teóricos que permitam visualizar quais devam ser os fatos escolhidos e quais os que devam ser desconsiderados. Situação análoga pode ser aduzida para uma eventual demarcação entre os contextos da descoberta e da justificação. Ora, a justificação constitui explicação legítima que tem lugar em algum momento histórico e como tal é também reveladora de antigas e/ou de novas descobertas à luz de novas perspectivas e isso também pertence à história dos conceitos.

Passemos agora do plano educacional/pedagógico ao plano epistemológico propriamente dito e vejamos o que subjaz às ideias de ordem da natureza tanto no que diz respeito à classificação comtiana das ciências quanto no que concerne à recomendação de que a Física deva ser a ciência ensinada logo em primeira instância no currículo escolar para somente depois ser ensinada a Química e em seguida ser ensinada a Biologia, sempre nesta ordem. Para tal, vamos nos situar nos séculos XX e XXI e não no século XIX no qual viveu Comte. Ora, a Física estuda as interações básicas entre os átomos e se nos reportarmos à Física Nuclear, esta ciência estuda as interações que têm lugar no núcleo do átomo; se admitirmos uma escala microscópica ainda menor, diríamos que a Física se atém às interações em nível das partículas elementares. As leis que buscam explicar esses níveis da realidade constituem a base para as leis de outro nível como o das ligações moleculares que dizem respeito à Química e essas, por sua vez, constituem a base do nível crescente em complexidade que é da Biologia com suas células que constituem o elemento básico dos seres vivos, e assim por diante.

Subjaz a essa concepção também a ideia de que qualquer nível acima é redutível aos níveis mais fundamentais e se formos levar esta concepção a extremos diríamos que as leis da Química podem ser reduzidas às correspondentes leis da Física que constituem o seu fundamento e as leis da Biologia às leis da Química e da Física numa instância ainda mais fundamental. Este é o ponto de vista de físicos como Feynman et. al. (1965), Weinberg (1994) e de certo modo Gell Mann (1996), mas tratase de um ponto de vista enormemente controverso que tem adversários de peso como Anderson (1972), Hamburger (1992), Schweber (1993), entre outros. Esses últimos autores não respaldam a redução, pois alegam que existem propriedades emergentes em certos níveis de realidade que são propriedades singulares daqueles níveis que são inerentemente irredutíveis a outros níveis supostamente mais fundamentais. Ademais, essa irredutibilidade, segundo os defensores deste ponto de vista, faz parte da própria ordem da natureza. Poderíamos conjecturar, ainda que provisoriamente, que para estes últimos, chamados genericamente de emergentistas, haveria grande autonomia entre tais níveis de realidade fato este que não respaldaria, no plano educacional/pedagógico, que o ensino 
de Física devesse necessariamente preceder o de Química e o de Biologia, pois esses, respeitandose as suas autonomias relativas de descrição em seus próprios níveis de realidade, poderiam ser ensinados em quaisquer ordens no currículo escolar. Vê-se perfeitamente que a ideia de pré-requisito tem uma contrapartida epistemológica clara e, além disso, certamente controversa.

Como exemplo dessa controvérsia no campo da epistemologia cita-se a postura de Ernst Mayr (19042005), biólogo evolucionista que nos últimos anos de sua vida dedicou-se à Filosofia da Ciência, ao afirmar que:

O que interessa no estudo de um sistema complexo é sua organização. Descer até o nível mais baixo de análise com frequência diminui o poder explicativo (...). Ninguém conseguiria inferir a estrutura e a função de um rim caso recebesse um catálogo de todas as moléculas de que está composto. Este argumento é válido não só para sistemas biológicos complexos, mas também para os inanimados. Se quiser entender a função e a natureza de um martelo, aplico as leis apropriadas da mecânica. Se for tentar analisar o martelo no próximo nível inferior e determinar, por exemplo, de que tipo de madeira é feito o cabo, e se em seguida estudasse a estrutura da madeira no microscópio, e continuasse descendo pela química até as moléculas, átomos e partículas elementares constituintes dos quais se compõe o cabo, eu não acrescentaria coisa alguma ao entendimento das propriedades do martelo enquanto martelo. (Mayr, 2005, p.89).

Podemos aventar um argumento de outro teor. Habitualmente a Física é ensinada tomando por base a Mecânica. Há razões históricas a respaldar essa tradição entre as quais a grande predominância da mecânica durante mais de um século. Se tomarmos como marco o ano da publicação dos Principia em 1687, expressão emblemática do apogeu da mecânica e da Gravitação Universal Newtoniana, e o ano de 1812 no qual foram publicados os trabalhos de Fourier sobre a propagação do calor, os quais faziam uso de um esquema teórico rival e qualitativamente diferente daquele ensejado pelas forças de contacto e pelas forças agindo a distância de Newton, veremos que foram, pelo menos, 125 anos de domínio quase exclusivo da Mecânica. Com Faraday, e ainda no século XIX surgiu, de maneira gloriosa, outro poderoso rival dos conceitos estritamente mecânicos que foi o conceito de campo.

Não obstante, o reconhecimento de que o mundo real é mais termodinâmico que mecânico e que a energia mecânica total do pêndulo real, e diferentemente da energia mecânica total do pêndulo ideal, vai se dissipando gradativamente em calor, a mecânica continua sendo base para as descrições da realidade do ponto de vista clássico. Mesmo no que tange aos fenômenos irreversíveis como os que envolvem o calor. Expressão deste fato é que embora o calor não seja redutível à mecânica, todas as energias, quaisquer que sejam elas inclusive o calor, devem ser escritas em termos das quantidades basilares da mecânica que são comprimento $L$, o tempo $T$ e a massa $M$. Deste modo, a dimensão física da grandeza física calor tem a dimensão $\mathrm{ML}^{2} \mathrm{~T}^{-2}$. Este balizamento pela mecânica é uma tradição que reforça a recomendação de Comte segundo a qual os fenômenos geométricos e mecânicos são dentre todos os mais fundamentais.

Este último argumento está em sintonia com uma das teorias de aprendizagem cognitiva de maior destaque em nossos dias: a Teoria de Aprendizagem Significativa de David Ausubel. Para Ausubel, existe uma estrutura cognitiva onde se processam a organização e integração de informações na mente do ser que aprende. Para ele, o fator isolado que mais influencia a aprendizagem é aquilo que o aluno já sabe [...]. Novas ideias e informações podem ser aprendidas e retidas, na medida em que 
conceitos relevantes e inclusivos estejam adequadamente claros e disponíveis na estrutura cognitiva do indivíduo e funcionem, dessa forma, como ponto de ancoragem às novas ideias e conceitos. [...]. Ausubel vê o armazenamento de informações no cérebro humano como sendo organizado, formando uma hierarquia conceitual, na qual elementos mais específicos do conhecimento são ligados (e assimilados) a conceitos mais gerais, mais inclusivos (Moreira, 1999, p. 152). Nesse sentido, e mais uma vez, as ideias positivistas de Comte de hierarquia das ciências fundamentais pela subordinação dos fenômenos naturais correspondentes, parece bastante pertinente para a compreensão, em si, do próprio fenômeno de aprendizagem, segundo Ausubel, entendida como a "ancoragem" de uma nova informação a um conceito subsunçor já existente na estrutura cognitiva do aprendiz, de modo que a nova informação interaja de forma não-arbitrária com os conceitos preexistentes e, dessa forma possa ocorrer uma aprendizagem significativa, que faça sentido para o sujeito.

\section{CONSIDERAÇÕES FINAIS A TÍTULO DE CONCLUSÃO}

Neste trabalho, elegemos como objetivo a procura de uma resposta, ainda que parcial sobre uma eventual e possível influência positivista de lavra comtiana no movimento Physics First. Deste modo, a proposta do presente estudo foi a de discutir e refletir em que medida o movimento Physics First guarda, e se guarda, uma herança positivista em seus princípios mais fundamentais. Uma resposta ponderada a esta pergunta não deverá se constituir como algo concebido a priori em que o positivismo já aparece demonizado, pois misturaríamos influências más e boas colocando-as todas em um mesmo padrão, procedimento este que comprometeria sobremaneira a nossa análise. De fato, a moderna epistemologia critica severamente a concepção positivista como algo ultrapassado e sem correspondência com o desenvolvimento da ciência. As suas etapas estanques e lineares do desenvolvimento tanto humano quanto histórico são insustentáveis à luz da ciência hodierna pelas razões aqui extensivamente comentadas.

Fazemos coro da ideia segundo a qual o positivismo é contradito tanto pela história quando pelos desenvolvimentos mais recentes da ciência, pois esse detesta (ou ignora a contribuição) imaginação e conjecturas, dois dos pilares talvez mais importantes das modernas teorias científicas. Mas nada disso condena o positivismo como corrente que não seja capaz de levantar problemas importantes e férteis, mesmo nos dias atuais, e isso seguramente ele foi capaz de fazer. A própria ideia da necessidade de uma educação científica que fosse concebida mediante atalhos e dentro de um Programa Educacional compatível com os tempos teve e ainda tem ampla repercussão e não podemos dizer que essa repercussão seja necessariamente má. Ela, de fato, carrega elementos pertinentes e que não podem ser desconsiderados. Se, de fato, há traços comuns entre as ideias subjacentes ao movimento Physics First e a doutrina positivista da ciência, isso não é de desprezível significação. A discussão sobre os diversos níveis de realidade se são redutíveis uns aos outros segundo ordens mais fundamentais, ou, ao contrário, se, de fato, há uma descontinuidade essencial na descrição quando se passa de uma ordem fundamental da realidade para outra, constitui problema que se atém tanto à doutrina positivista quanto à concepção de ensino do movimento Physics First. E trata-se de contribuição relevante. 


\section{REFERÊNCIAS}

AAPT - American Association of Physics Teacher. (2006). Physics First. An Informational Guide for Teachers, School Administrators, Parents, Scientists, and the Public. In: www.aapt.org/Policy/physicsfirst.cfm. Acesso em out/2010 e dez/2019.

ANDERSON, P. W., (1972) More is Different, Science, vol. 177, p. 393.

BASTOS FILHO, J. B. (2005), Reducionismo (Uma abordagem epistemológica), Maceió: Editora da Universidade Federal de Alagoas (EDUFAL).

BRAGA, M. GUERRA, A. \& REIS, J. C. 2008. O Papel dos Livros Didáticos Franceses no Século XIX na Construção de uma Concepção Dogmático-Instrumental no Ensino de Física. Cad. Bras. Ens. Fís. Vol. 25, n. 3, pp. 507-522. Disponível em: http://www.periodicos.ufsc.br/index.php/fisica/article/view/9085/8453.

BRASIL, Conselho Nacional da Educação. Base Nacional Comum Curricular, Resolução CNE/CP No 2 de 20 de dezembro de 2017.

BROCKINGTON, G. \& PIETROCOLA, M., 2005, Serão as regras da transposição didática aplicáveis aos conceitos de física moderna?, Investigações em Ensino de Ciências, Vol. 10, n. 3, pp. 387-404, 2005. http://www.if.ufrgs.br/ienci/artigos/Artigo ID136/v10 n3 a2005.pdf

CHEVALLARD, Y. La Transposición Didáctica: del saber sabio al saber enseñado. La Pensée Sauvage, Argentina, 1991.

COMTE, A. (1988, publicado originalmente em 1830). Os Pensadores, tradução de José Arthur Giannotti e Miguel Lemos. São Paulo: Nova Cultural.

COSTA, A. y DOMÈNECH, G. (2002). Distintas lecturas epistemológicas en tecnología y su incidencia en la educación. Enseñanza de las Ciencias, 20(1), p. 159-165.

FEYNMAN, R. P.; LEIGHTON, R. B.; SANDS, M., (1965) The Lectures on Physics, Vol. 1, Massaschusetts: Addison-Wesley, Reading.

GELL-MAN, M. (1996) O quark e o jaguar (As aventuras no simples e no complexo), Rio de Janeiro: Rocco.

HAMBURGER, J. (1992). Paixão e Razão, Rio de Janeiro: Livraria Francisco Alves Editora S. A.

HOLT, R. (2002). What's so special about science? The Physics Teacher, vol. 40, p. 135.

GLASSER, H. M. (2012). The numbers Speak: Physics Supports Math Performance. Physics Teacher, v. 50, n. 1, p. 53-55.

JUNGES, A. L.; SANTOS, V. Y.; MASSONI. N. T.; SANTOS, F. A. C. (2018). Efeito estufa e Aquecimento Global: uma abordagem conceitual a partir da física para educação básica. Experiências em Ensino de Ciências, vol. $13, \quad$ n. $\quad 5, \quad$ p. $126-151$. http://if.ufmt.br/eenci/artigos/Artigo ID531/v13 n5 a2018.pdf.

KARNAL, L. et. al. (2010). História dos Estados Unidos das origens ao séc. XXI. São Paulo: Editora Contexto. 
LAKATOS, I., (1979), O Falseamento e a Metodologia dos Programas de Pesquisa Científica, In: A Crítica e o Desenvolvimento do Conhecimento, Lakatos I. \& Musgrave A, (Orgs.) São Paulo, Cultrix, Editora da Universidade de São Paulo, 1979, pp. 109-243

LEDERMAN, L.M. (2005). Physics first? The Physics Teacher, vol. 43, no 1, p. 6-7.

MAMONE CAPRIA, M. (2004), Complessità, riduzionismo e teorie finali in fisica, Iride, ano XVII, n. 41, pp. $95-107$

MASSONI, N. T. (2010). A Epistemologia contemporânea e suas contribuições em diferentes níveis de Ensino de Física: a questão da mudança epistemológica. Tese de Doutorado, IF-UFRGS.

MATTHEWS, M. R. (1995). História, filosofia e ensino de ciências: a tendência atual de reaproximação. Caderno Catarinense de Ensino de Física, vol. 12, no. 3, p. 164-214.

MATTHEWS, M. R. (2009a). Science, worldviews and education: an introduction. Science \& Education, vol. 18, n. 6-7, p. 641-666.

MATTHEWS, M. R. (2009b). Teaching the philosophical and wordview components of science. Science \& Education, vol. 18, n. 6-7, p. 697-728.

MAYR, E. (2005). Biologia, Ciência Única. São Paulo: Companhia das Letras, 266 p.

MOREIRA, M. A. (1999). Teorias de Aprendizagem. São Paulo: E.P.U., 195 p.

PENROSE, R., El camino a la realidad (una guía completa de las leyes de universo), México: Debate (1a impressão, 2008), [Título original The Road of Reality, publicado por Jonathan Cape, Londres, 2004].

RAICIK, A. C., \& PEDUZZI, L. O. Q. (2015). Potencialidades e limitações de um módulo de ensino: uma discussão histórico-filosófica dos estudos de Gray e Du Fay. Investigações em Ensino de Ciências, 20(2), 138-160. DOI:10.22600/1518-8795.ienci2016v20n2p138.

RAPOSO, W. L. (2014). História e Filosofia da Ciência na Licenciatura em Física, uma proposta de ensino através da pedagogia de projetos. Caderno Brasileiro de Ensino de Física, 31(3), 722-738. DOI: $10.5007 / 2175-7941.2014 \mathrm{v} 31 \mathrm{n} 3 \mathrm{p} 722$.

RINALDI, E., \& GUERRA, A. (2011). História da ciência e o uso da instrumentação: construção de um transmissor de voz como estratégia de ensino. Caderno Brasileiro de Ensino de Física, 28(3), 653675. DOI: $10.5007 / 2175-7941.2011 v 28 n 3 p 653$.

SHEPPARD, K., \& ROBBINS, D. M.. (2003). Physics was once first and was once for all. The Physics Teacher, vol. 41, p. 420-423.

SHEPPARD, K., \& ROBBINS, D. M. (2009). The "First Physics First" Movement, 1880-1920. The Physics Teacher, vol. 47, Issue 1, p. 46-50.

SCHWEBER, S. S., (1993) Physics, Community and the Crisis in Physical Theory, Physics Today, novembro de 1993, pp. 34-40

WEINBERG, S., (1994), Dreams of a final theory (The scientist's search for the ultimate laws of Nature), New York: Vintage Books.

WILLIAMS, W.F. (1983). The responsibility of scientists. Physics Education, vol. 18, no 3, p. 110/114. 